American Journal of Applied Sciences 5 (5): 504-511, 2008

ISSN 1546-9239

(C) 2008 Science Publications

\title{
A Review of Problem Solving Capabilities in Lean Process Management
}

\author{
${ }^{1}$ A.P. Puvanasvaran, ${ }^{2}$ M.H.M.A. Megat, ${ }^{2}$ S.H.Tang, ${ }^{1}$ Muhamad, M.R and ${ }^{3}$ A.M.S. Hamouda \\ ${ }^{1}$ Faculty of Manufacturing Engineering, University Technical Malaysia, Karung Berkunci 1200, Ayer \\ Keroh, 75450 Melaka, Malaysia \\ ${ }^{2}$ Department of Manufacturing Engineering, University Putra Malaysia, \\ 43400 Serdang, Selangor, Malaysia \\ ${ }^{3}$ Mechanical and Industrial Syatems Engineering, Qatar University, Doha, Qatar
}

\begin{abstract}
Human factor plays an important role in ensuring lean process management to be successful and provides good proposition for the success of the organization in the long run. One of the main elements of people is their problem solving capability in identifying and eliminating wastages. The purpose of this paper was to review problem solving capabilities in lean process management; and identifying the important factors and needs for lean process management. Beside that the paper also proposed the conceptual framework of people development system which can help organizations to enhance employees' capability in identifying and eliminating wastages continuously and effectively.
\end{abstract}

Keywords: Lean Process Management, Problem Solving Capabilities, Respect for People, Key Performance Indicator, Skill and Knowledge

\section{INTRODUCTION}

Traditionally an organization is seen as a collection of departments or activities, each managed separately with their own inventories or time buffers between them, while performance is improved by setting targets and budgets. When the targets are not met the management finds an easy way out, that is structural changes in the organization, which does not address the real issues such as the underlying processes and cost structures that remain more or less unchanged.

An organization is usually made up a collection of customer processes, design and production processes and many support processes that enable these values creating processes to flow. Therefore the actual task is to identify the values in each of these processes, to see and manage the end-to-end flows and to synchronize the support flows.

The main task is to help the managers to see their processes and to uncover the reasons why there is no flow in the process. This includes the impossibly complex mix of products that flow through the processes by challenging the batch logic of the planning systems; scheduled for every product or batch through every operation. This process creates the conditions where we can begin to flow most products through the entire process and at the same time assures the stability necessary to develop standard operations in every process step, which is the baseline for continuous improvement.

There is a need to identify the individual processes and the flow of the organization as a whole. This exposes the management and employees to more opportunities to improve the process. The distinctive thing about lean thinking is that it derives from observing the best practices in an organization.

As such it is the accumulation of the experience of thousands of employees in solving problems that enable processes to flow and in line with customer's demand. Lean process management then, is to assist any types of organization with a desire to improve the company's operations and become more competitive by focusing on cost reduction that eliminates non-value added activities.

A scientific approach is needed in order to solve and improve the problem solving close to its source. Every problem is an opportunity to improve the process and every problem is also an opportunity to develop people. As such it is important to consider the best way to overcome the interruptions and hiccups in the processes. There is a need for a common approach to problem solving across the organization and a common

Corresponding Author: $\quad$ A.P.Puvanasvaran, Faculty of Manufacturing Engineering, University Technical Malaysia Melaka (UTeM), PO Box 1200, Ayer Keroh, 75450, Melaka, Malaysia, Tel: +606-2316694, Fax: +606-2332414 
language for communicating the diagnosis and the results. This includes for a policy deployment framework for aligning and prioritizing problem solving activities in line with the business goals of the organization. The managers' role to lead by developing the abilities of their staff to solve problems, at every level in the organization and throughout their career is very crucial in lean process management.

In the present dynamic business nature, leanness has undergone and still going a process of continuous and never ending evolution ${ }^{[5]}$. Since the introduction of the Toyota Production System, the lean concept has spread all over the world. The principle of lean manufacturing, of which process improvement is an important element was brought to the attention of the West by the publication of "The Machine that Changed the World" by Womack et al. ${ }^{[2]}$. This was followed by "Lean Thinking"[1], which was more practitioner focused. In addition, there have been many Japanese inspired books which focused on company's specific production systems ${ }^{[3,4,6]}$. Since then process improvement has been adopted by many companies and there have been many case studies from companies outlining their successes in process improvement ${ }^{[7]}$.

On the other hand Bateman $^{[8]}$, relates process improvement with sustainability by identifying enablers associated with activities. Process improvement activities are a crucial tool for companies undergoing lean transformation and removing waste from their processes and he has suggested conducting more analytical study into what sustains the improvement made by these activities.

There have also been a number of papers trying to identify what can be done to improve sustainability. Bessant et al. ${ }^{[9]}$, in their CIRCA project (Continuous Improvement Research for Competitive Advantage) identify that there are different issues associated with the setting up of a CI program and sustaining it. They stated that some of the factors associated with maintaining momentum for CI include lack of commitment, lack of training, cultural clashes, and other factors.

Sustainability is also an issue with other types of improvement program. Dale et al. ${ }^{[10]}$, identify those factors that negatively impact on sustaining total quality management by studying a number of case study companies. They divide these negative impact factors into five categories: internal/external environment, management style, policies, organizational structure and process of change. He concludes that a number of factors affected the sustainability in their case-study companies including inadequate leadership, failure to complete projects, and others.

Lean manufacturing is usually accompanied by a shift towards exposure and solving of problem ${ }^{[11]}$. This change calls for a new approach in problem solving. Boyer $^{[12]}$, mentioned that teamwork and group problem solving is a critical component of TQM and JIT. Besides that, teamwork and group problem solving serve to crash barriers and to improve the flow of information through a company, thus leading to improved productivity. Working as groups, while utilizing appropriate problem solving techniques, it will increase efficiency and pride in work improvement outputs $^{[13]}$.

Jorgensen et al. ${ }^{[14]}$, examine the role of the team leader in continuous improvement. In their longitudinal case study based in Denmark, it is identified that there was a gap in perception between the senior management and team leaders in terms of enablers that were in place. The senior managers perceived enablers to be fully present in the organization whereas in reality they were in place in name only. Bhuiyan and Baghel $^{[15]}$, have suggested without active involvement of everyone in the organization, and required resources and support from top management; if not continuous improvement cannot be successful. In addition, they have commented that only little focus given towards developing a framework or model enable organization to identify $\mathrm{CI}$ best needs

According to two researches conducted by Boyer $^{[12]}$ and Soriano-Meier ${ }^{[16]}$, there are two major issues that will influence the implementation of lean manufacturing in an organization. They are management commitment to lean manufacturing and manufacturing infrastructure investment. In their research, they focused on four infrastructural investments: quality leadership, group problem solving, training, and worker empowerment.

Womack and Jones ${ }^{[1]}$ and Worley and Doolen ${ }^{[17]}$ stated, management that fails to embrace the implementation of lean process may interrupt the effort. Top management should not only demonstrate commitment and leadership, it must also work to create interest in the implementation of lean process and communicate the change to everyone within the organization. Management must be committed to the project and involve themselves in the lean manufacturing events. If employees feel that the management team does not respect their efforts, discouragement may appear and the lean manufacturing effort will fail. Though it is often desirable to drive change from the factory floor, it is important that a 
conversion to lean manufacturing be driven by the executive management team.

Another key to successful lean practice is worker empowerment, defined as giving workers more responsibility and control of the manufacturing process [12]. This is because only employees can identify ways of improving the existing process of product ${ }^{[11]}$. Worley and Doolen ${ }^{[17]}$, research findings identified management support and communications as important variables in a lean manufacturing implementation. Furthermore, there is evidence that these variables are critical in not only the implementation of lean manufacturing practices and principles, but also in the ongoing planning and deployment efforts of organizational leaders.

A case study specifically on one of the lean tools by Mary ${ }^{[18]}$ at Cooke Brothers Ltd focus on effective implementation of $5 \mathrm{~S}$ depends upon commitment by management at top level and total involvement of staff at all levels within firm. However, his study shows that a firm's culture, communication and employee attitudes are the factors that influence success or failure in the use of the 5Ss.

Peter Hines et. al, ${ }^{[19]}$, comments on approaches that have sought to address some of the earlier gaps in lean thinking. They provide a framework for understanding the evolution of lean not only as a concept, but also its implementation within an organization. They too found that the distinction of lean thinking at the strategic level and lean production at the operational level is crucial to understanding lean as a whole in order to apply the right tools and strategies to provide customer value.

Gary J. Vroman ${ }^{[20]}$, highlights that current European aerospace business is also changing because of industry consolidation. Ladish is an aerospace industry wanted to be well-positioned when the down cycle ended and next up cycle began, so the organization embarked on a program to improve the effectiveness of the decisions made by its engineers. One of the major systems that drove the development of the company is lean thinking methodology.

\section{Key performance indicator in Lean process} management: Systematically implementing improvement actions based on customer expectation and strategic decisions through business processes, and prioritizing improvement actions will definitely contribute to strategic objective of process management ${ }^{[21]}$. Workers initiatives and combined with their enablers directly link down the strategy of those activities at the operating level of the business which contribute most to manufacturing excellence ${ }^{[22]}$.
Upton $^{[23]}$, looked at features of successful improvement initiatives in his paper. Two of the features are emphasis based on clear targets and common understanding of direction which involves a unifying picture to hold the improvement programmed together and consistent focus on improvement which means using the picture identified above and using previous improvement activities to direct new activities.

Timothy and Clinton ${ }^{[24]}$, suggest that goal setting and timely feedback will lead to improved work performance, greater efficiency, and the establishment of more challenging goals. It provides significant insight into ways to improve productivity through the use of goal setting and performance feedback implemented by information systems.

Respect for people in Lean process management: Top managers who practice Lean management must make greater efforts to ensure that they understand the true meaning of kaizen - "change for the better" - and the "continuous improvement" and "respect for people" principles ${ }^{[25]}$. This paper describes how an important principle of lean process management, "respect for people," was not understood by most management practitioners, thus hindering efforts to correctly practice Lean management and improve business performance.

Emiliani and Stec ${ }^{[26]}$, examine why most Lean transformations achieve only modest favorable results, despite years of effort. They provide specific suggestions that will enable senior managers and organizations to achieve improved outcomes and identifies numerous common errors made by senior managers, the rationale for why the errors have occurred, and suggests improvements for implementing the Lean management system by seeking to implement a Lean transformation; Senior managers must realize that they are embracing for the first time a principlebased system of management whose objective is to change the way all work activities are performed, not just those in operations.

Emiliani $^{[27]}$, focused on Continuous personal improvement. Success with lean can be limited unless recognize the behaviors of employees that changes in business process. The study produce the model which serves as a foundation for those familiar with world class manufacturing methods to focus on selfimprovement efforts and useful as a mnemonic device to simplify the difficult task of personnel development, as well as ensure consistency between business process and group of individual behavior.

Emiliani ${ }^{[28]}$, which defined behaviors that add or create value by minimization of waste associated with 
arbitrary or contradictory thought and actions that leads to defensive behavior, ineffective relationship, poor cooperation, and negative attitudes. While fat behavior is defined as behaviors that add no value and can be eliminated. They include the display of irrational and confusing information that results in delays or work stoppages, or the articulation of unsubstantial subjective thoughts and opinions. It clearly states that common fat behaviors that result in waste and selected lean behaviors that promote flow between people.

According to a case study on Motorola by Alan Larson $^{[29]}$, behavior is important to change culture to sustain implement of lean concept. Many efforts failed due to the behavior of management. Employees will follow the management behavior if they are ordered to do new things. Motorola has used a people-centered approach to drive fundamental change.

Clare $^{[30]}$, states that seven best practice components must be present in order to apply lean. They are environment change, leadership, culture, employee empowerment, training, communication, measurement. These components first bring changes in the management's behavior which will then influence the employees to practice the seven component.

Motwani ${ }^{[31]}$, through means of a case study, discusses a successful lean manufacturing implementation experience at a medium-size automation manufacturing company in the Midwest region of the USA. Specifically, he examines the Strategies, Significant benefits, and critical factor utilizing Business process change framework that facilitated and inhibited the success of Lean Manufacturing at the case study company. He has adapted a model of Business process change management in his work. From Kettinger and Groover's one of the significant business process requirements highlighted is the cultural readiness.

Bhasin and Burcher ${ }^{[32]}$, in a study found a cocktail of factors for lean success is focused not only on the necessity to implement most of the technical tools but an organization's culture too needs transformation. This statement was supported by John ${ }^{[33]}$ who has done the survey and qualitative data provides evidence that workers' resistance to learning is part of the contested arena of productivity and job control.

Skill and knowledge in Lean process management: Kumar and Harms ${ }^{[34]}$, reports learning and application of a few significant techniques to improve basic business practice in company, which manufacture large volume, high quality thin optical thin film coating by identifying opportunities for improving operational efficiencies including analysis of current business processes, identification of non-value -added activities including wastes and proposing process change. Their finding concluded that to be successful, a company must educate their workforce and create a fulfilling work environment for each of their employees because their involvement is essential and critical in today's society and gaining workers' trust and commitment is extremely important.

Boyer $^{[12]}$, stated the successful implementation of lean production rely on well-trained employees. In a lean production environment, training is necessary in order to develop a workforce which is capable of shouldering the increased responsibility, to develop multi-skilled workers, and to create an environment in which workers have the skills and ability to push for continuous improvement. By referring to Womack et al. $^{[2]}$ and Boyer ${ }^{[12]}$, concludes that plants which allocate greater resources for the training of the workforce have been shown to have increased productivity.

David Woodcock ${ }^{[35]}$, discusses the link between various forms of shop floor workers competencies and the ability of manufacturing plants to compete on different forms of market attractiveness and show how movement along a four-level model of competence, ranging from operator proficiency to high levels of problem-solving ability affects a firm's ability to support improvements in different dimensions of competitiveness.

Steven $^{[36]}$, in his working paper discusses on the structuring process improvement efforts to deepen problem solving skill that requires managers to reshape their roles. It has become essential for managers to develop "dynamic capabilities" so that their organizations could adapt to and exploit changes in the competitive environment".

\section{FOCUS OF THE PROCESS}

The main focus of lean process is to reduce cost by eliminating non-value added activities; labeled as waste in every organization which either produce products or provide services. The problem solving capability of the employees is another important factor that derives the system successfully, including the cooperation of everyone from top to bottom. The main reason of this paper is to review and highlight the importance of total teamwork in an organization with three integration elements; which are Respect for people, Key performance indicator (KPI) and Skill and Knowledge. These three elements of lean process management form 
the people development system in enhancing problem solving capability among the employees.

Although a number of authors have discussed the issues outlined above, they fail to provide a structured lean process management system that can guide employees in creating problem solving capabilities when implementing the processes. Moreover, despite literature suggesting 'what' and 'why' an organization needs and have practice for process improvement, it fails to state 'how' it should improve process especially to create problem solving capability among employees to make it sustain. Furthermore, past studies only focus at individual integration element and do not really focus on lean process management.

In today's competitive world, no company can afford to waste resources. The most underutilized resource of most manufacturing company is their people. The number one asset of any organization also is its people. In fact, people are one of the few appreciating assets an organization has. The real advantages of employee's involvement are to focus a group of employee with different perspective on a single objective that support the organization's strategic focus. The companies that develop and leverage the capabilities of all their employees will achieve better performance than those that do not. The companies that fail to unlock the potential of their workforce will be forced to carry more overhead, have more layers of management, and will be slower to react.

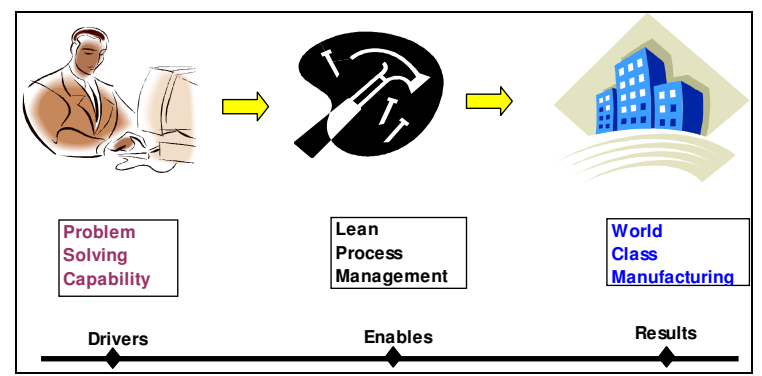

Fig. 1: Illustration of Lean success model towards achieving World class Manufacturing

It is hard to deny that most of the manufacturing companies that are focusing on company strategy for cost reduction through eliminating wastages are remain to sustain in this competitive world. Lean process management definitely becomes their arms to fight to achieve this goal. Figure 1 illustrates clearly on the employees capability in problem solving as they become the drivers to enable the lean process management as a tool to achieve excellence in work processes through respects for employees to deliver consistent Quality products and zero complaint from internal and external customers with lowest cost of operation which is the expected results of the process.

Lean Process Management System: Lean Process Management System enables any types of organization to reduce or eliminate wasteful practices. It is an integrated system developed and refined over the course of more than a decade. In addition, it is used to establish standardized conditions and methods to eliminate opportunities for waste. This has become a very difficult task for every manager and employees who are responsible for solving problems to further improve the processes of eliminate waste.

People Management System: People management systems are those activities, practices, and procedures that will empower the company's people. They provide the direction and challengers in the development of people. This system assists the employees in the implementation of the company's business plan. Included in such system are employee education program, focused involvement teams, and self-directed work groups. People management system reduces the red tape typical of most traditional companies. They allow decision making to be leveraged and made at the lowest level that is realistically possible. In order to realize this tremendous benefit, people need to arm with clear objectives and proper skill sets. Unfortunately, these requirements are not common in the classic pyramid type of organization structure.

Business Management System: Business management systems are the company's practices, policies and procedures. They plan and direct the activities of the organization's personals in applying company resources to satisfy customer requirements. These systems include a company's compensation and reward system, organizational structure, distribution systems and management of supply chain. Business management system are critical because no company has unlimited resources. The winners in manufacturing are those who understand how to maximize the amount of value they add while minimizing the resources they require to add this value. The most precious resources in today's manufacturing and business world in general is time.

Objective of the three Systems: Each of the three systems has an objective. The objective of the lean process management system is to identify and eliminate wastages by removing non value added activities. People management systems need to provide the 
capability for rapid improvement and adoption to change. Here, again, we must accept the fact that change is inevitable and that the speed with which the necessary modification are made is the deciding factor in our survival. The objective of the business management system is to apply carefully the organization's limited resources, including capital and hard assets as well as time and human assets.

\section{DISCUSSION}

Three integration elements with total employee involvement from top to bottom play an important role for sustaining problem solving among employees in practicing lean concept. It is important to create people development system which consists of all these three elements with total involvement of people to increase problem solving capability.

People management system, Business management system and Lean process management system are integrated by principles that, in a sense, hold them together. These principles are meant to provide a framework (Fig. 2) to focus the direction in enhancing problem solving capability among employees by forming as people development system in lean process management. They are:

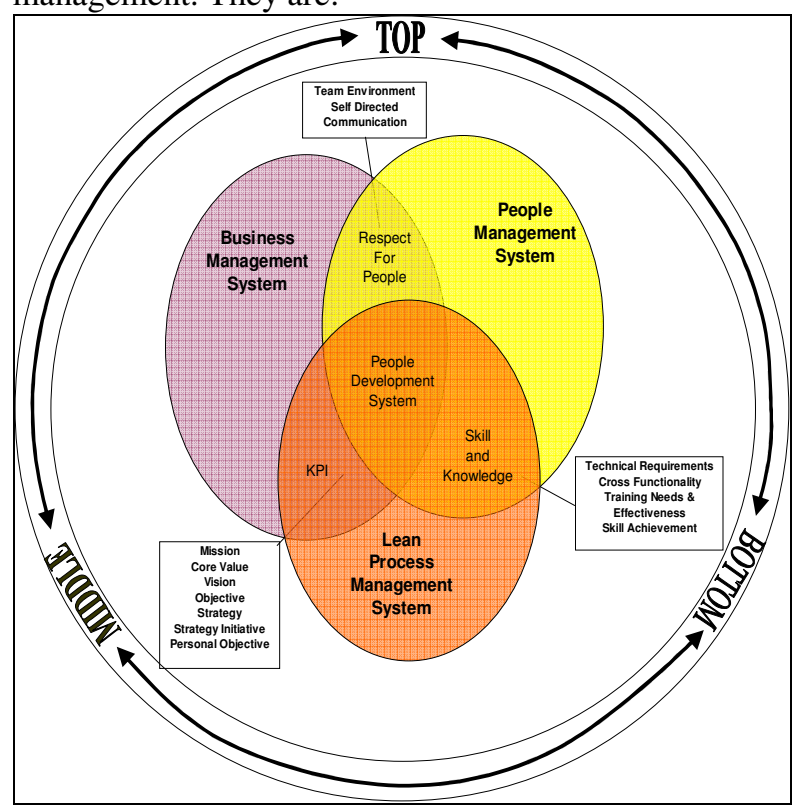

Fig.: 2 Framework for Enhance Problem Solving Capabilities among Employees

- Key performance indicator - KPI for every level such as company, department, section and individual levels which is link towards organization goal.

- Respect for people - Respect for people which mainly focuses on the lean behaviors that each employee in organization should build in their mind.

- Skill and Knowledge - Skill and Knowledge for employees will support them in practicing lean concept effectively and efficiently by utilizing the lean tool and techniques.

Another important element incorporated with this people development system framework is teamwork of top, middle and bottom management. The total commitment of all these three levels will enhance of problem solving capability in lean process management among employees.

Key characteristic, critical success factors (CSF) and related performance matrix: The following key characteristics, CSFs and related performance metrics are identified as crucial in people development system of lean process management as in Table 1 below.

Table 1: An analytical framework for measuring problem solving capability in lean process management

\begin{tabular}{|c|c|c|}
\hline $\begin{array}{c}\begin{array}{c}\text { Key characteristics of } \\
\text { integration elements }\end{array} \\
\end{array}$ & $\begin{array}{l}\text { Critical success factors (CSF) of } \\
\text { People Development System }\end{array}$ & Performance Matrix \\
\hline KPI & \multirow[b]{2}{*}{$\begin{array}{l}\text { Customer Satisfaction } \\
\text { On Time Delivery } \\
\text { Zero Defect } \\
\text { Cost reduction } \\
\text { Effective Operation Cost }\end{array}$} & \multirow[b]{2}{*}{$\begin{array}{l}\text { Achievements of KPI for each } \\
\text { level versus goal/target. } \\
: \text { Productivity } \\
: \text { Customer complain } \\
: \text { Scrap/Number of reject } \\
\text { : Attendance/ Absenteeism } \\
: \text { Tardiness (Schedule time) } \\
\text { - Use QCDAC principles. }\end{array}$} \\
\hline $\begin{array}{l}\text { Mission } \\
\text { Core Value } \\
\text { Vision } \\
\text { Objective } \\
\text { Strategy } \\
\text { Strategy Initiative } \\
\text { Personal Objective }\end{array}$ & & \\
\hline Respect for people & & \\
\hline $\begin{array}{l}\text { Team Environment } \\
\text { Self Directed } \\
\text { Communication }\end{array}$ & $\begin{array}{l}\text { Top Management Commitment } \\
\text { Team effectiveness/formation } \\
\text { Ideas cost or value } \\
\text { Continuous improvements } \\
\text { Lean Behaviors } \\
\text { Rewarding system }\end{array}$ & 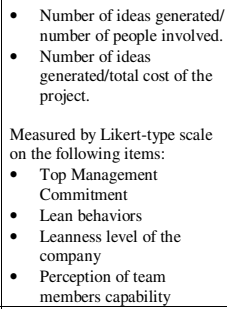 \\
\hline $\begin{array}{l}\text { Skill and Knowledge } \\
\text { Technical Requirements } \\
\text { Cross Functionality } \\
\text { Training Needs \& Effectiveness } \\
\text { Skill Achievement }\end{array}$ & $\begin{array}{l}\text { Produce skilled, knowledgeable and } \\
\text { innovative employees }\end{array}$ & $\begin{array}{l}\text { - Lean tools and techniques } \\
\text { assessment } \\
\text { - Employee skill metric }\end{array}$ \\
\hline
\end{tabular}

- KPI in lean process management determination through Mission, Core Value, Vision, Objective, Strategy, Strategy Initiative and Personal Objective for people development system is crucial. This will align overall workforce of the company to follow for one common goal. Each level has its own portion of contribution towards the target. The results are compared with the target or goal used to measure the 
success of KPI. The accumulation of success from each portion will reflect the overall achievement of the company goal.

- Respect for people in lean process management is another crucial factor in developing the lean culture throughout organization. In order to measure the lean behaviors, top management commitment, leanness level of the company and perception of team member's capability, Likert-type scale is used to get the responses from respondent. For example, one can ask managers to rate the degree of support by top management on five-point scale from no support (1) to total support (5). Beside this, the problem solving capability also can be measured by counting the number of ideas generated, number of people involved and the total cost of the project.

- Skill and Knowledge in lean process management is the fundamental requirement for employees to equip themselves. Without this they can't perform well in solving problem to identify and eliminate wastages. Lean tools and assessment techniques by using assessment criteria to determine the level of implementation using spider web chart with rating of 1 (beginning to introduce) to 5 (practice with excellent). Another measurement on employee skill metric will emphasize on employees skill and their cross functionality.

\section{CONCLUSION}

The review of various journals clearly reveals and indicates the importance of introducing lean process management for the organization to sustain and be more productive and profitable. So far the researches conducted in this field do not provide a clear framework that can enhance problem solving capabilities among employees in implementing lean process management. The review also found that there is a need to integrate People management system; Business management system and Lean process management so that a concrete platform can be established to enforce the lean concept effectively.

The proposed People Development System framework in this paper is expected to contribute to the production of a management manual and shop floor workbook with the aim to enhance problem solving capability among employees in implementing Lean process management. The management manual focuses on the policy and strategy of people development system for top management use. While the Shop floor work book suggests on, 'How to' for middle and bottom employees use. The measurement model for people development system was developed to measure the results of people problem solving capabilities from top to bottom level. There is a potential for the implementation of this People Development System framework in the industries especially in the aerospace industry.

\section{ACKNOWLEDGEMENTS}

The author would like to acknowledge the University Technical Malaysia Melaka for the scholarship granted.

\section{REFERENCES}

1. Womack, J.P. and Jones, D.T., 1996. Lean Thinking, Simon and Schuster, London.

2. Womack, J.P., Jones, D.T. and Roos, D., 1990. The Machine that Changed the World, Rawson Associates, New York.

3. Ohno, T., 1996. The Toyota Production System: Beyond Large Scale Production, Productivity Press.

4. Shingo, S., 1997. A Study of the Toyota production system from an industrial engineering Viewpoint, Productivity Press.

5. Papadopoulau, T.C., Ozbayrak, M., 2006. Leanness: experiences from the journey to date, Journal of Manufacturing Technology Management, 16: 784-807.

6. Cusumano, M., 1985. The Japanese Automobile Industry: Technology and Management at Nissan and Toyota, Harvard University Press, Cambridge, MA.

7. Jowit, J., 1999. A dirty job that someone's got to do well, Financial Times, pp. 6, 7 December.

8. Bateman, N., 2005. Sustainability: the elusive element of process improvement, International Journal of Operations \& Production Management, 25: 261-276.

9. Bessant, J., Caffyn, S. and Gilbert, J., 1994. Mobilizing continuous improvement for strategic advantage, EUROMA, 1: 175-180.

10. Dale, B., Boaden, R., Willcox, M. and McQuater, R., 1997. Sustaining total quality management: what are the key issues, TQM Magazine, 9: 37280 .

11. Forrester, R., 1995. Implications of lean manufacturing for human resource strategy, Work Study, 44: 20-24. 
12. Boyer, K.K., 1996. An assessment of managerial commitment to lean production, International Journal of Operation \& Production Management, 16: 48-59.

13. Gatchalian, M.M., 1997. People empowerment: the key to TQM success, The TQM Magazine, 9: 429433.

14. Jorgensen, F., Boer, H. and Gertsen, F., 2003. Jump-starting continuous improvement through self assessment, International Journal Operations \& Production Management, 23: 1260-78.

15. Bhuiyan,N.,Baghal,A., 2005. An overview of CI: the past to the present", Management Decision, 43: 761-771.

16. Soriano-Meier, H. and Forrester, P.L., 2002. A model for evaluating the degree of leanness of manufacturing firms, Integrated Manufacturing System, 13: 104-109.

17. Worley J.M., Doolen T.L., 2006. The role of communication and management support in a lean manufacturing implementation, Management Decision, 44: 228-245.

18. Mary O'hEocha., 2000. A study of the influence of company culture, communications and employees attitudes on the use of $5 \mathrm{Ss}$ for environmental management at Cooke Brothers Ltd, The TQM Magazine, 12: 321-330.

19. Peter Hines, Matthias Holweg and Nick Rich, 2004. Learning to evolve: A review of contemporary lean thinking, International Journal of Operations \& Production Management, 24: 9941011.

20. Gary J Vroman, 1999. Sharpening the problemsolving skills of aerospace engineering Aircraft engineering and Aerospace Technology: An International Journal, 71: 255-258.

21. Carpinetti, L.C.R., Gerolamo, M.C. and Dorta M., 2000. A conceptual framework for deployment of strategy-related continuous improvement, The TQM Magazine, 12: 340-349.

22. Gilgeous, V. and Gilgeous, M., 1999. A framework for manufacturing excellence, Journal of Manufacturing system, 10: 33-44.

23. Upton, D., 1996. Mechanisms for building and sustaining operations improvement, European Management Journal, 14: 215-28.
24. Timothy C. S., Clinton O. L., 2006. The effects of goal setting and feedback on manufacturing productivity: A field experiment, International Journal of Productivity and Performance Management, 55: 346-358.

25. Emiliani, M.L., 2006. Origins of lean Management in America: The role of Connecticut businesses, Journal of Management History, 12: 167-184.

26. Emiliani, M.L., Stec D.J., 2005. Leaders lost in transformation", Leadership \& Organization Development Journal, 26: 370-387

27. Emiliani, M.L., 1998. Continuous personal improvement, Journal of workplace learning, 10: 29-38.

28. Emiliani, M.L., 1998. Lean behaviors, Management Decision, 36: 615-631

29. Alan, L., 1997. Case study: Guiding cultural change at Motorola, Management Development Review, 10: 185-187.

30. Comm Clare L., 2005. A case study in applying lean sustainability concepts to universities, International Journal of Sustainability in Higher Education, 6: 134-146.

31. Motwani, J., 2003. A business process change framework for examining lean manufacturing: a case study, Industrial Management \& Data System, 103: 339-346.

32. Bhasin, S., and Burcher, P., 2006. Lean viewed as a philosophy, Journal of Manufacturing Technology Management, 17: 56-72.

33. John, A.B., 2001. Why workers are reluctant learners: The case of Canadian pulp and paper industry, Journal of Workplace learning, 13: 333343.

34. Kumar, S. and Harms, R. 2004. Improving business processes for increased operational efficiency: A case study, Journal of Manufacturing Technology Management, 15: 662-674.

35. David Woodcock, 1996. How skills development affects manufacturing's competitive capability, Integrated manufacturing system, MCB University Press, 7: 38-44.

36. Steven J.S., 2003. Building process improvement capacity: Structuring problem solving as skillbuilding exercises, working paper: 02-006. 